\title{
Signos Étnicos na Moda no Século XXI: Manifestações culturais pré- colombianas na criação de produtos atemporais
}

Ethnic Signs in the $21^{\text {st }}$ century's fashion: Pre-Columbian Cultural manifestations in creation of atemporal products

Andreia Salvan Mestranda em Design- UEMG andreiasalvan@uol.com.br

Caroline Pagnan

Doutoranda em Design- UEMG carolinespagnan@gmail.com 


\section{Signos Étnicos na Moda no Século XXI: Manifestações culturais pré- colombianas na criação de produtos atemporais}

Ethnic Signs in the 21st century's fashion: Pre-Columbian Cultural manifestations in creation of atemporal products

\section{Andreia Salvan e Caroline Pagnan}

\section{Resumo}

A cultura se manifesta por meio dos saberes, crenças, lendas, costumes e modos de viver de um povo, os quais podem ser deslocados e reinterpretados num produto de moda que se espera ser observado por um interpretante carregado de bagagem ou acervo cultural. A inovação formal é reativada na moda a cada instante com formas mais aberrantes e mais arbitrárias, no plano estético, com o único fim de fornecer um material sempre novo de signos distintos. Ao retratar aspectos culturais na moda seja no vestuário ou nos acessórios, o seu caráter de efemeridade se reduz, uma vez que objetos ou produtos mais atemporais são propostos. Este artigo busca uma revisão acerca da relevância das manifestações culturais e das etnias na moda do século XXI, além de fazer uma abordagem do processo criativo de uma coleção de acessórios com referências nas culturas pré-colombianas dos povos Incas, Maias e Astecas.

Palavras- chave: Moda; cultura précolombiana; signos étnicos.

\begin{abstract}
The culture is manifested through knowledge, beliefs, legends, customs and ways of life of a people, which can be moved and re-interpreted in a fashion product that is hoped to be observed by an interpreter loaded with cultural background. The formal innovation is reactivated in fashion every moment with more aberrant and arbitrary forms, on the aesthetic level, with the sole purpose of providing an ever-new material of different signs. By portraying cultural aspects in fashion whether in clothing or accessories, it's ephemerality character is reduced, since more timeless objects or products are proposed. This article aims seeks a review of the relevance of cultural events and ethnic groups in the fashion of the century, in addition to making an approach to the creative process of a collection of accessories with references in preColumbian cultures of the people Incas, Mayas and Aztecs.
\end{abstract}

Keywords: fashion; pre-Columbian culture; ethnic signs. 


\section{Introdução}

A cultura possui o importante papel de socializar o homem no seu ato de comungar dentro do seu convívio com os modos e costumes adquiridos no seu meio. De acordo com Laraia (2002), o homem é resultado do meio cultural em que foi socializado, e como herdeiro de um longo processo acumulativo, reflete o conhecimento e sua experiência adquirida pelas numerosas gerações que o antecederam. De acordo com Taylor (1871) o termo cultura, quando estudado no sentido etnográfico, inclui conhecimentos, crenças, arte, moral, leis, costumes ou qualquer outra capacidade que o homem tenha adquirido como membro de uma sociedade. A moda exerce o papel de propagadora tanto dos aspectos estéticos como simbólicos presentes nas diversas culturas, características das várias etnias.

Por meio da linguagem presente nas roupas e nos acessórios, a moda estabelece um diálogo com o interpretante, sendo este responsável por uma leitura embasada em seu acervo cultural. Sob este ponto de vista, as roupas e acessórios criam símbolos que veiculam ou intermediam a comunicação com o interlocutor. Para White (1955), toda cultura depende de símbolos, e o que a perpetua é o exercício de simbolização que a sociedade cria. Tais símbolos devem ter uma forma física, caso contrario não poderão penetrar na experiência do indivíduo, porém, seu significado não pode ser percebido pelos sentidos. É necessário um conhecimento sobre a cultura que criou o símbolo para que o significado seja percebido.

Sob o aspecto da linguística, de acordo com Barthes (1996), o símbolo foi eliminado em proveito do signo, o qual carrega consigo a união de um significante e um significado. Em alguns casos a separação entre significado e significante torna-se difícil, mas a subdivisão forma/substância torna-se útil quando um sistema de objetos comporta uma substância que não é imediata e funcionalmente significante, mas pode ser simplesmente utilitário. Muitos sistemas semiológicos como objetos, gestos ou imagens têm uma substância da expressão cujo ser não está na significação. A roupa, por exemplo, serve para proteção, mas possui também a função de significar. A função reapresentada corresponde a uma segunda instituição semântica que é da ordem da conotação. Possui provavelmente um valor antropológico, já que é a própria unidade em que se estabelecem as relações entre o técnico e o significante. 
Nesse sentido, Moles (1981) define o objeto como "mediador universal, revelador da sociedade na progressiva desnaturalização desta, construtor do ambiente cotidiano, sistema de comunicação social", demonstrando que os objetos assumem uma série de papéis e funções nas interações com os indivíduos. O autor defende uma passagem progressiva do objeto-função, no sentido de sua utilidade, ao objeto de comunicação, sendo que a função de transmissão da mensagem ultrapassa a própria função que contribuiu para sua criação.

Para que o objeto de moda cumpra seu papel como signo, se faz necessária a atuação do interpretante, que carrega consigo um acervo cultural proveniente do meio onde vive e das suas percepções acerca dos aspectos culturais. Para Farbiarz et al (2006), o ponto de vista do observador ou interlocutor depende do seu repertório, o qual pode ser entendido como vocabulário, estoque de signos conhecidos e utilizados por um indivíduo. Além de conhecimentos técnicos, compõem o repertorio os valores éticos, estéticos, filosóficos, políticos, a ideologia do individuo, do grupo ou da classe social.

A influência do repertório na interpretação do objeto-signo é muito relevante, tendo importante papel, também, o processo criativo do indivíduo. De acordo com Ostrower (1987) o comportamento criativo do ser humano se baseia na interação entre três campos que constituem sua personalidade: o consciente, o sensível e o cultural. A consciência e a sensibilidade vêm de carga biológica, sendo que o indivíduo teria essas mesmas características em qualquer contexto no qual estivesse inserido. Já a cultura depende das relações que o indivíduo realiza ao longo de sua evolução, sendo a cultura transmitida, não herdada, o que significa que um indivíduo que é criado longe de sua família não terá a cultura da família, mas do ambiente no qual cresceu. $O$ desenvolvimento biológico do ser humano depende do desenvolvimento cultural do mesmo, concluindo-se, dessa forma, que a cultura serve de referência a tudo o que o indivíduo é, influenciando fortemente tudo o que o mesmo possa criar. Outro aspecto de grande importância para a construção do repertório do ser humano destacado, ainda, pela autora é a memória, com informações começando a ser acrescentadas à esse acervo já na infância, permitindo que comecem a ser estabelecidas ligações entre conteúdos para solucionar situações na vida desse indivíduo. 
Com a finalidade de ilustrar o processo de criação contido na metodologia de projeto de design como mediador dessa tradução cultural em objetos de moda, será apresentada a coleção desenvolvida pela marca de acessórios Mapoula, que propôs uma direção conceitual baseada na cultura pré-colombiana recombinando os usos, costumes, saberes, mitos e lendas dos povos Incas, Maias e Astecas. A leitura e observação da fauna e da flora presentes nos países pesquisados permitiram o uso da biomimética, que consiste na análise dos sistemas naturais e na reprodução dos seus princípios de solução, permitindo a criação de formas ou funções análogas (DETANICO; TEIXEIRA; SILVA, 2010). O estudo histórico destas culturas ofereceu subsídios para a geração dos aspectos estéticos e formais das peças como colares, pingentes, brincos e estampas têxteis.

\section{As manifestações culturais pré-colombianas na moda do século XXI}

A sociedade burguesa buscava igualar-se à nobreza no modo de se vestir numa busca por pertencimento, descrito por Simmel (2008) como um processo entre classes inferiores e superiores. O processo evolutivo da sociedade converge em comportamentos aspiracionais diferentes daqueles baseados nas classes mais altas por parte das classes mais baixas, as quais passaram a criar suas próprias referências intraclasse. O caráter de diferenciação atribuído aos produtos de moda continua a existir, mas esses carregam consigo referências dentro dos próprios grupos. Um esquema de distinção social descrito por Lipovetsky (2003) como a chave soberana da inteligibilidade da moda que, tanto na esfera do vestuário como na dos objetos e da cultura moderna, é incapaz de explicar a inconstância, as grandes mutações organizacionais e estéticas da moda.

Para Baudrillard (1996), uma análise da função dos objetos na moda mostra uma circulação acelerada, demonstrando uma mobilidade social que não existe de fato. Assim, a mudança de automóvel surge da impossibilidade de mudar de apartamento, o que mostra que a renovação acelerada dos objetos compensa muitas vezes uma aspiração frustrada face a um progresso social e cultural. Dessa forma, a moda e o consumo mascaram a inércia social profunda. Sob a ótica de que a moda se apresenta na frequência cíclica de objetos, de vestes e ideias, se exerce e se desmancha a exigência de mobilidade social efetiva. O seu caráter efêmero que elimina herança de signos distintivos parece oferecer a cada instante do ciclo a igualdade de oportunidades. Porém, 
no lugar de uma igualdade de todos diante dos objetos, por ser uma cultura de massa, a moda fala a todos para devolver cada um a seu lugar.

A efemeridade da moda toma o lugar das representações culturais presentes nos trajes típicos que carregam um teor de significados acerca das vivências e costumes de uma sociedade. Segundo Lipovetsky (2009), os trajes típicos culturais quase se extinguiram do uso cotidiano com o impulso da confecção industrial. Também contribuíram para a sua extinção o impulso das comunicações de massa, da dinâmica dos estilos de vida e dos valores modernos que levaram não só a um desaparecimento dos múltiplos trajes regionais folclóricos, como à atenuação das diferenciações heterogêneas no modo de vestir das classes, se caracterizando por toaletes ao gosto do dia abrangendo camadas sociais cada vez mais amplas.

As características e detalhes presentes nos vestuários típicos podem ser vistas na moda em coleções com referências étnicas. As peças de vestuário criadas por Frida Kahlo retratam a cultura indígena simbolizada pelas flores bordadas nos huipil, trajes típicos confeccionados e usados pelas mulheres mexicanas de Tehuantepec (ZERBATO; ESTARQUE, 2013). A etnia maia, representada tanto nos trajes usados por Frida quanto nos quadros pintados por ela, recebem uma nova leitura na coleção primavera/verão de 1998 de Jean Paul Gaultier, na coleção primavera/verão 2014 de Alberta Ferreti e na coleção primavera/verão 2016 de Osman Yousefzada. Esses criadores fizeram uma nova interpretação dos aspectos culturais já interpretados pela artista mexicana e os difundiram para outras culturas.

O processo de interpretação da cultura e sua transposição para a moda permitem a sua difusão, uma vez que ela ultrapassa fronteiras geográficas. De acordo com Laraia (2002), os antropólogos estão convencidos de que não seria possível o grande desenvolvimento atual da humanidade sem a difusão. A antropologia denomina difusão os empréstimos culturais que são realizados por cópias de outros sistemas culturais.

\section{Métodos}

Para o desenvolvimento da coleção Etrum, a empresa Mapoula, incubada na Incubadora de Empresas e Negócios de Design situada na Escola de Design da Universidade do Estado de Minas Gerais (UEMG), teve como finalidade a criação de produtos que despertassem o interesse do usuário por sua história. O processo criativo 
se baseou na resignificação de elementos existentes nas culturas pré-colombianas Inca, Maia e Asteca. De acordo com Garcia (2014) a recombinação se baseia no deslocamento de algo que já existe com o objetivo de produzir o efeito de novidade. As imagens usadas como referências foram poucas, uma vez que as fontes de referências foram, em sua maioria, textuais obtidas em livros de mitologia, história e acervos de museus. O processo consistiu na criação de um sistema denominado por Barthes (1996) como a descrição de algo presente no imaginário coletivo, não por seus "temas", mas por sua forma e função, ou mais: por seus significantes e significados.

A metodologia de projeto adotada pela empresa foi composta a partir da união de ferramentas e métodos utilizados pelo design de moda e pelo design de produto, por meio de pesquisas textuais e imagéticas acerca do tema, interpretação e definição dos conceitos a serem seguidos, construção de painéis imagéticos, geração de alternativas para uma linha de produtos com amplas possibilidades, passando pelo acompanhamento da produção através dos processos de corte a laser, fotocorrosão, aplicação de resina, estamparia digital, modelagem, corte e costura, partindo para a produção do catálogo e material de divulgação chegando até a inserção dos produtos no mercado, carregando consigo alto valor cultural e funcional.

Dentro da temática das culturas pré-colombianas, após a pesquisa foram selecionados os países representantes de cada cultura, sendo selecionados, além do Brasil, o Peru como representante da cultura Inca, a Guatemala como representante da cultura Maia e o México como representante da cultura Asteca. Cada um dos quatro países teve suas lendas, costumes e arquitetura presentes em sua cultura pesquisados de forma aprofundada, sendo posteriormente materializados nas formas geométricas características como identidade da marca. A arquitetura de cidades pré-colombianas como Machu Picchu, Tikal, Monte Alto, foram, juntamente a diversos outros itens, referências fortemente presentes nos elementos representados tanto nas estampas aplicadas em lenços e bolsas quanto nas formas de peças de metal e acrílico aplicadas em colares, brincos, braceletes, cintos.

\section{Estampas têxteis baseadas na cultura dos incas}

A civilização inca existiu na América do sul do ano 1200 até a invasão dos conquistadores espanhóis e a execução do imperador Atahualpa em 1533. A cidade 
atual de Cuzco fora a capital do império, que possuía como idioma mais falado o Quíchua. Local muito visitado hoje, Cuzco abriga o templo do sol construído com pedras encaixadas. Junto a outros templos, ele representa uma religião que cultuava suas divindades, baseada no politeísmo que envolvia o sacrifício de animais. A arte dos incas serviu de referência para a geração de estampa impressa digitalmente em tecido destinado à confecção de bolsas com detalhes em couro como mostra a Figura 1(c). A Figura 1(a) mostra a imagem de referência das artes dos incas caracterizada por formas geométricas abstratas que representavam detalhes de deuses ou animais estilizados. A Figura 1(b) apresenta a estampa desenvolvida com a união de referências na geometria aplicada pelo povo inca, as cores comumente aplicadas além dos animais e outros elementos presentes nas lendas populares que compõem a cultura peruana perpetuada por gerações de acordo com Moraes (2002).

FIGURA 1(a)-a arte dos incas; 1(b)- estampa têxtil criada; 1(c)- bolsa Yucatãn

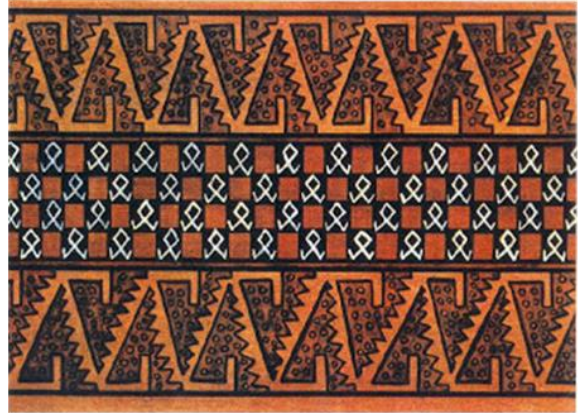

(a)

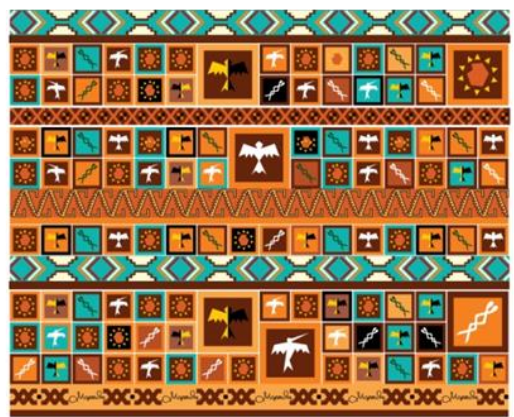

(b)

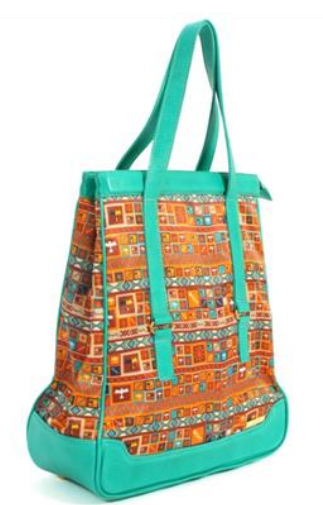

(c)

Fonte: http://a-aprender-historia.blogspot.com.br/2014/01/civilizacoes-amerindias-incas-os-incas.html

\section{O culto aos animais sagrados nas antigas civilizações americanas}

A civilização maia se estendeu aos nativos americanos do sul do México e América Central, e é forte esta cultura atualmente em alguns estados mexicanos, em Belize, na Guatemala, Honduras e El salvador. De acordo com Grube (2006), nas partes mais altas da Guatemala encontram-se as maiores e mais conservadoras populações maias, onde é possível observar a manutenção dos costumes e tradições culturais por meio de trajes típicos e uma identidade local específica. Segundo Vásquez e Rendón (1948), as tradições e crenças religiosas se concentram nos livros de Chilam Balam, 
encomendado por padres das localidades originárias da península de Yucatãn, a qual abrange territórios do México, Cuba e Guatemala. São textos que descrevem a história pré-hispânica e colonial, trazendo elementos importantes como calendários, astrologia e ervas medicinais dentro da visão religiosa do povo maia, numa compilação dos manuscritos dos séculos XVII e XIX.

Além de uma crença religiosa politeísta, os maias cultuavam os animais e algumas vezes os sacrificavam como oferendas para estabelecer relações com o mundo dos deuses. De acordo com Henderson (2008), a oferenda do sacrifício humano pode ser vista como um mistério, expresso em um ato ritual cujo simbolismo permite recuar muito na história humana. Um rito que possui um clima de tristeza misturado a uma certa alegria devido à revelação interior de que a morte leva o homem a uma nova vida. Simbolicamente representam a libertação do homem de qualquer forma de vida restritiva, no curso da sua progressão rumo a um estágio superior ou mais amadurecido da sua evolução.

Na mitologia grega é possível encontrar símbolos animais como Zeus, o pai dos deuses, que muitas vezes se aproxima das jovens sob a forma de cisne, um touro ou uma águia. Outros podem ser vistos na mitologia germânica, como o gato consagrado à deusa Freya, enquanto que o javali, o cavalo e o corvo são consagrados à Wotan (HENDERSON, 2008).

FIGURA 2(a)- pássaro Quetzal ; 2(b)- moeda da Guatemala; 2(c)- pingente de colar quetzal

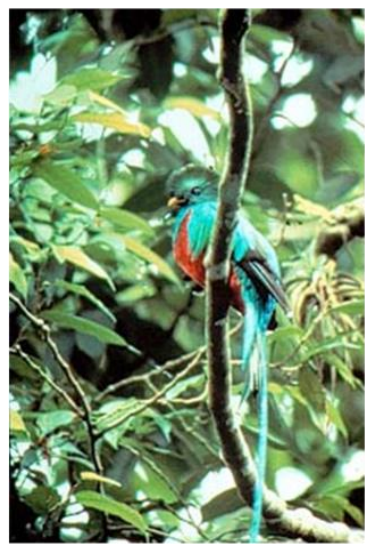

(a)

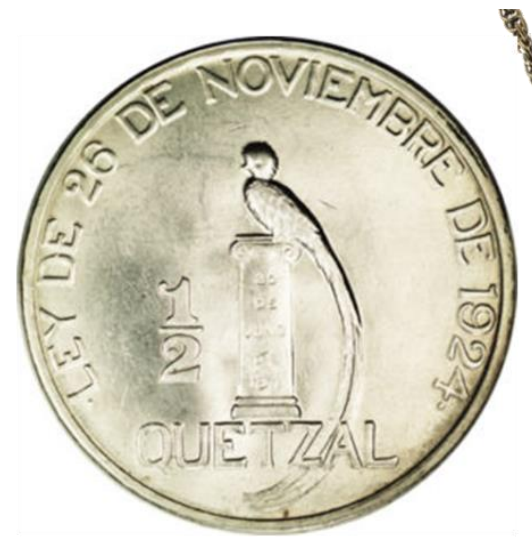

(b)

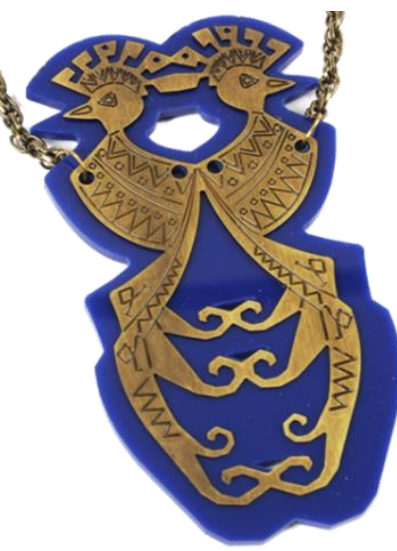

(c)

Fonte: https://simple.wikipedia.org/wiki/Resplendent_quetzal 
O pássaro Quetzal, uma espécie nativa das florestas do México e da Guatemala é uma ave cultuada pelos antigos povos maias e astecas. Denominado também como "serpente de penas", possui plumagem verde-esmeralda com reflexos dourados como pode ser visto na Figura 2(a), e possui modos de vida solitários, tendo dificuldades de sobrevivência em cativeiro, o que o faz desse modo ser cultuado como pássaro da liberdade. Sua imagem está presente na moeda da Guatemala como mostra a Figura 2(b). O produto final é um pingente em metal desenvolvido pela técnica de fotocorrosão sobre uma base de acrílico cortada a laser como mostra a Figura 2(c). A peça vem acompanhada de tag com texto explicativo sobre a história da ave e sua simbologia, o que coloca o usuário em contato com o significado do seu aspecto formal.

Tanto no universo da bijuteria como da joia se faz necessária uma percepção por parte do usuário acerca dos aspectos físicos e formais que conferem simbologia à mesma. De acordo com Balaguera (2013) as joias trazem consigo uma mensagem transmitida por quem as criou, tornando-se, por sua vez, resultado de quem as interpreta.

\section{A crença politeísta presente na religião dos Astecas}

Os Astecas também tinham sua crença politeísta cultuando como principal deidade Quetzacóatl, uma divindade das culturas mesoamericanas. Ao chegar ao Vale do México, incorporaram a crença, porém eliminaram alguns rituais como os sacrifícios humanos. Sua representação é feita na figura de uma "serpente emplumada" por simbolizar as energias telúricas que ascendem. Também significa o alimento físico e espiritual para o povo que o cultua.

A ressignificação na forma de um produto da imagem construída pela cultura asteca de uma "serpente emplumada" foi feita mediante geração de formas que viessem a ser um signo com o significado de proteção para o usuário. De acordo com Braga (2004), o adorno usado pelo homem no período pré-histórico foi uma forma encontrada para se impor entre os demais. Mostrou sua bravura ao se adornar com dentes e garras de ferozes animais. Mas, além do caráter de proteção, tais adornos possuíam o caráter de magia, associando os seus objetos de uso a poderes fora dos normais. 
A Figura 3(a) mostra a imagem idealizada pelos astecas do Quetzacóatl, ou "serpente emplumada", a qual serviu de referência para a geração de alternativas ilustradas na Figura 3(b). O produto final é um colar composto por acrílico cortado a laser e metal desenvolvido pela técnica de fotocorrosão com subsequente banho de ouro amarelo como mostra a Figura 3(c).

FIGURA 3 (a)- Quetzacóatl ; 3(b)- Geração de formas; 3(c) Produto final

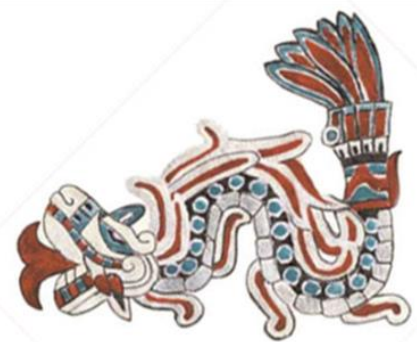

(a)

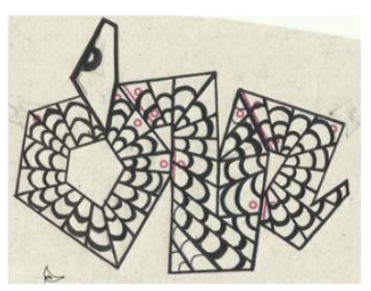

(b)

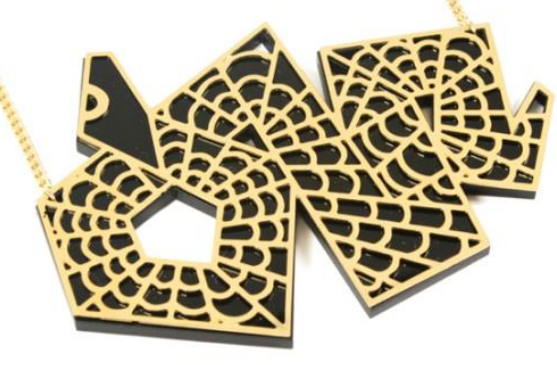

(c)

Fonte: http://edicionesepopteia.com/El-Vuelo-de-la-Serpiente-Emplumada/

Dentro de um contexto histórico e cultural, os acessórios e as joias possuem um valor baseado não apenas no material, mas principalmente em seu significado. Criaram por exemplo, de acordo com Gola (2008), uma contradição cultural no Brasil entre os colonizadores e indígenas, de forma que, uma pulseira de penas para o povo indígenas possua tanto valor quanto uma pulseira de diamantes na cultura europeia, sendo que tal valor atribuído seja proporcional à raridade do pássaro.

Considerando o poder conferido pelos adornos e joias sob o aspecto religioso, o seu uso e função foram se valendo de novos repertórios dentro de um processo evolutivo histórico. Durante as conquistas de terras e as descobertas de minas de ouro o uso das joias simbolizava poder, assim como as joias bizantinas que refletiam as promessas de imortalidade com as figuras de Cristo e da Virgem. Já as joias góticas, outro exemplo, traziam inscrições que enalteciam o amor e a mulher dentro de um conceito de cortesia e cavalheirismo típicos da Idade Média (TEIXEIRA, 2001).

\section{As lendas e os costumes dos povos incas como referência}

A civilização Inca, apesar de antiga, só veio a se estabelecer com mais força a partir do século XII influenciando territórios do norte do Chile, Bolívia, Equador e uma 
maior predominância no Peru. Centralizavam o poder nas mãos de um soberano inca, que na língua quíchua significa "o filho do sol”, o qual era considerado quase um deus. Desenvolveram grande habilidade com os metais empregando em suas artes o cobre, o bronze, o ouro e a prata, despertando a cobiça dos conquistadores.

Como politeístas, acreditavam em deuses da natureza como a chuva, a lua, o sol e o trovão, assim como nas lendas que carregam uma magia ou transformação. A lenda da Garça Branca, segundo Moraes (2002) conta a história de uma linda menina chamada Branca que vivia com seus pais e seus dois irmãos à beira do rio Ucaiali. Ela possuía, dentre muitas habilidades, a de comer peixes com espinhos sem se engasgar o que despertou a inveja em seus dois irmãos, que solicitaram a um feiticeiro que a transformasse em uma ave. Atendendo ao pedido o feiticeiro a transformou em uma garça branca, da cor do vestido que Branca sempre usava. A lenda conta que hoje a garça vive nas margens dos rios e utiliza suas habilidades na busca de peixes. Com base nas referências textuais foram geradas alternativas dentro da identidade da marca, como mostra a Figura 4(a). Utilizando linhas geométricas em uma forma de recombinação, foi materializada uma linguagem escrita de uma antiga cultura. A figura 4(b) mostra um colar com o desenho de quatro garças dispostas de forma espelhada confeccionado em metal com banho de ouro amarelo. A Figura 4(c) mostra um design de superfície com aplicação da forma aprovada, a qual foi rotacionada criando uma estampa localizada para aplicação em lenços de tecido por meio da técnica de estamparia digital.

FIGURA 4(a)- Geração de desenhos; 4 (b)- Colar Garça; 4(c)- Estampa têxtil localizada

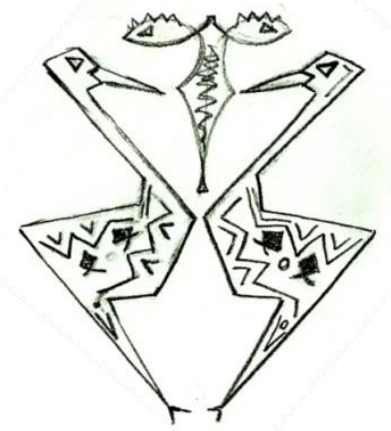

(a)

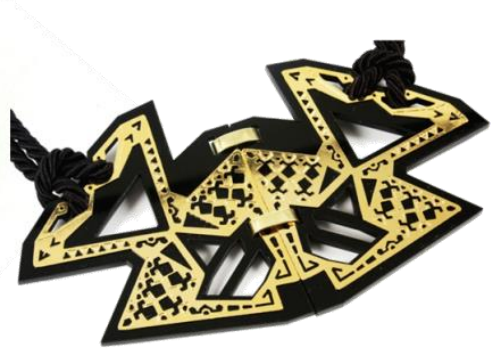

(b)

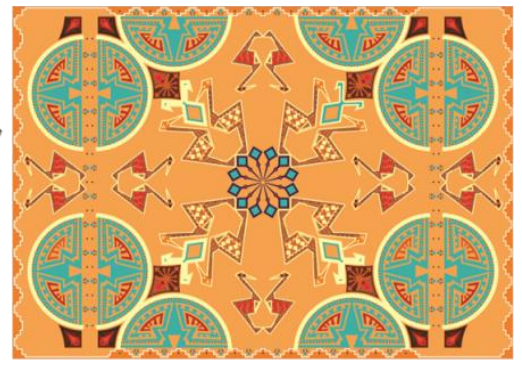

(c)

Fonte: acervo pessoal (2014)

De acordo com Henderson (2008), os "símbolos de transcendência" são aqueles que representam a luta do homem para alcançar seu objetivo. Ao ser transformado num 
pássaro, a força reside na faculdade que lhe é atribuída de conseguir separar-se do corpo para voar pelo universo, além de se tornar uma espécie de médium capaz de ter conhecimento de acontecimentos distantes.

\section{Conclusões}

O uso de referências culturais na moda é um processo que já podia ser notado nas roupas modeladas por Madeleine Vionnet nos início do século XX se inspirava nas esculturas da Antiguidade Clássica grega (Braga, 2004). Na busca pela valorização dos aspectos geográficos, de fauna e flora brasileiras, Zuzu Angel realizou uma difusão cultural ao levar para as passarelas internacionais estampas e bordados que mostravam a identidade brasileira. Em sua coleção de inverno 2015 desfilada no quinto dia da semana de moda em Paris no mesmo ano, Vivienne Westwood se inspirou na tribo peruana Ashaninka que havia visitado há uns anos atrás. Usou de formas e cores da cultura local que conferiram um estilo de roupas de caráter atemporal. O que pode ser visto é que o processo criativo baseado no uso das referências culturais permite a geração de produtos de moda atemporais. Além de estabelecer uma comunicação com o interpretante por meio de um signo criando significados que contam sobre os costumes, lendas de um povo e sua cultura, os acessórios e joias carregam o significado de proteção e poder ao usuário.

Sudjic (2010) defende que os objetos são a maneira de o indivíduo medir a passagem de sua vida, sendo usados para definir essa pessoa e sinalizar o que ela é ou não é, podendo esse papel ser assumido ora por joias, ora por móveis, ora pela roupa. $\mathrm{O}$ design é apontado como a linguagem responsável por confeccionar a mensagem que esse objeto carrega, sendo os designers capazes de manipular essa mensagem.

Dessa forma é importante salientar como o design, atuando como mediador dessa tradução de identidades culturais em objetos, possui grande capacidade de unir os aspectos presentes na cultura que lhe serve de referência, os aspectos técnicos e funcionais envolvidos quanto à processos produtivos, ergonômicos e materiais e o contexto do interpretante, encontrado no papel do usuário daquele produto, carregando suas necessidades e expectativas. Ao unir essa gama de fatores, o designer é capaz de gerar um produto que vá além de sua função básica, sendo o portador de uma mensagem um significado, se tornando um signo. 
Artigo recebido em Maio de 2016. Aprovado em Junho de 2016

DOl:http://dx.doi.org/105965/1982615x09182016043

\section{Referências}

BALAGUERA, Y.L.S. La influencia de los materiales en el significado de la joya. Cuaderno del Centro de Estudios en Diseño y Comunicación, n. 46, p. 115-153, 2013.

BARTHES, Roland. Elementos de semiologia. 4. ed. São Paulo: Cultrix, 1996.

BAUDRILLARD, J.Função-signo e lógica de classe. in: A Economia Política dos Signos. São Paulo: Editora Martins Fontes, 1996. Pág. 9-49.

BRAGA, J. Historia da moda: uma narrativa. São Paulo: Anhembi Morumbi. 2004 DETANICO, F.B.; TEIXEIRA, F.G; SILVA, T.K. A Biomimética como Método Criativo para o Projeto de Produto. Design \& Tecnologia, n. 2, 2010. Disponível em

http://www.pgdesign.ufrgs.br/designetecnologia/index.php/det/article/viewFile/52 133. Acesso em 15 de abril de 2015.

FARBIARZ, Alexandre; FARBIARZ, Jackeline Lima; NOJIMA, Vera Lucia dos Santos. Os quatro ventos da comunicação. In: COELHO, Luiz Antonio L. (org.). Design método. Rio de Janeiro: Ed. PUC-Rio; Teresópolis: Novas Idéias, 2006. p.64-86

GARCIA, Carol. Recombinações: Auditions Brasil 2014. Disponível em: < http://www.auditionsbrasil.com.br/tag/recombinacoes/>. Acesso em: 23 de novembro de 2014.

GOLA, E. A Joia: História e design. São Paulo: SENAC/SP, 2008.

GRUBE, N. Maya: Divine Kings of the Rain Forest. Cologne: Könemann Press, 2006. 
HENDERSON, J.L. Os mitos e o homem moderno. In:JUNG, C.G. O homem e seus símbolos. Rio de Janeiro: Nova fronteira, 2008, cap. II, p.133-205.

LARAIA, R. B. Cultura: um conceito antropológico. Rio de Janeiro: Jorge Zahar, 2002.

LIPOVETSKY, Gilles. O Império do Efêmero: a moda e seu destino nas sociedades modernas. São Paulo: Companhia da Letras, 2009.

MOLES, Abraham A. Teoria dos Objetos. Rio de Janeiro: Edições Tempo Brasileiro, 1981.

MORAES, A. D. de. Contos e lendas do Peru. WMF Martins fontes, 2002.

OSTROWER, Fayga. Criatividade e processo de criação. Petrópolis: Vozes, 1987.

SUDJIC, Deyan. A Linguagem das Coisas. Tradução por Adalgisa Campos da Silva. Rio de Janeiro: Intrínseca, 2010.

TEIXEIRA, M.B.S. Design de joias em Minas Gerais. A construção de uma identidade. In: CASTAÑEDA, Cristiane; ADDAD, J. E; LICCARDO, Antonio. Gemas de Minas gerais. Belo Horizonte: Ed. SBG, 2001, cap. 10, p.261-280.

VÁSQUEZ, B.; RENDÓN, S. (translators). El Libro de los Libros de Chilam Balam: Traducción de sus textos paralelos. Mexico: Fondo de Cultura Económica, 1948.

WHITE, L. "The symbol: the origin and basis of humans behavior", in Morbel, Lennings e Smith (orgs), Readings of Antropology. Nova York: McGraw-Hill Book Co, 1955.

ZERBATO, B. N.; ESTARQUE, M. M. Frida Kahlo: Figurinista de si mesma. In: Colóquio de Moda, 9., 2013, Fortaleza. Anais eletrônicos... Fortaleza: UFC, 2013. Disponível em: < http://www.coloquiomoda.com.br/anais/anais/9-Coloquio-deModa_2013/POSTER/EIXO-7-FIGURINO_POSTER/Frida-Kahlo-Figurinistade-si-mesma.pdf> Acesso em: 21 de jan. 2016. 